\section{Ipsilateral cerebral hemorrhage following deployment of the Pipeline Embolization Device}

\author{
Kyle M. Fargen, M.D., M.P.H., And Brian L. Hoh, M.D.
}

\begin{abstract}
Department of Neurosurgery, University of Florida, Gainesville, Florida
\end{abstract}

Flow-diversion devices have advanced the treatment of cerebral aneurysms. The Pipeline for the Treatment of Uncoilable and Failed Aneurysms (PUFS) ${ }^{1}$ investigational trial evaluating the Pipeline Embolization Device (PED; ev3-Covidien) led to FDA approval of the device in April 2011. The results of treatment with the PED were excellent in multiple studies that have followed. ${ }^{2,9,12,13} \mathrm{In}$ addition, recent cost-effectiveness analyses have favored flow diversion over stent-assisted coiling, particularly for large or giant aneurysms. ${ }^{3,4,6}$

In the earliest studies evaluating the PED, an uncommon and unexplainable, yet catastrophic, phenomenon was noted. Our group reported a case of a delayed ipsilateral parenchymal hemorrhage occurring 5 days after PED placement that ultimately was fatal. ${ }^{14}$ In the PUFS trial, $5 \%$ of patients developed parenchymal hemorrhages, ${ }^{1}$ and in another series of 101 aneurysms treated with PED by Fischer and colleagues ${ }^{9} 3 \%$ of patients developed such hemorrhages. Our group summarized the literature and reported a $2 \%$ incidence of unexplained delayed ipsilateral parenchymal hemorrhages after PED treatment. ${ }^{8}$ The authors of a more recent study of 47 patients with anterior circulation aneurysms reported similar hemorrhages in $8.5 \%$ of their patients. ${ }^{7}$

Because the etiology of these hemorrhages was unexplained, several hypotheses have been proposed. One potential explanation was based on the changes in hemodynamic capacitance of the parent vessels after placement of the PED, which could result in hyperperfusion of diseased or fragile vessels downstream, leading to parenchymal hemorrhage in the supplied territory. This hypothesis is supported by the fact that cerebral hyperperfusion has been demonstrated after PED placement. ${ }^{5}$ An alternative hypothesis was hemorrhagic transformation of embolic periprocedural infarcts in the setting of dual antiplatelet therapy. An argument against the second hypothesis is that while emboli are common after PED use (in up to
$52 \%$ of patients ${ }^{10}$ ), such delayed hemorrhages are not seen in patients receiving antiplatelet therapies for elective coil embolization, in which periprocedural embolic events are also common.

$\mathrm{Hu}$ et al. performed histopathological analyses of specimens obtained in 3 patients who died after PEDassociated delayed intracranial hemorrhages. ${ }^{11}$ Surprisingly, in each case the authors found evidence of foreign embolic material within the distal vasculature of the hemorrhagic lesion. On further inspection with spectroscopy, the foreign material was discovered to be polyvinylpyrrolidone (PVP), a compound that forms the lining of many of the catheters used in neurointerventional procedures. While the authors could not definitively link the presence of the Cook Guiding Sheath-derived PVP material and the etiology of the 3 hemorrhages, they did identify an important phenomenon that was previously unknown to the neurointerventionist community. We can only assume that this link will be further clarified in the very near future.

We in the neurointerventional community must be accountable for identifying patient harm events and taking the initiative in preventing their future occurrence. This is particularly important when evaluating early-generation devices of new technologies, for which the results or complications may be difficult to interpret. As the physicians caring for these patients, we have the responsibility of questioning the events that we don't understand. Hu and colleagues should be congratulated for recognizing a serious patient safety issue and tackling it by performing an in-depth analysis of affected patients.

Neurointerventional techniques are being refined to optimize aneurysm occlusion while preventing ischemic injury due to thromboembolism. To this end, numerous devices have been developed to facilitate the goals of treatment. In addition, the use of a continuous heparinized saline flush, back bleeding, systemic heparinization, antiplatelet therapies and treatments have become the standard to minimize embolic events during these procedures. The discovery of emboli containing foreign materials after PED usage introduces a new problem. Consider these new questions that must be answered: What devices release materials during procedures? How often does embolization occur? What causes the release of materials to occur? How can it be prevented? Do we need to rethink the compounds we are using in our devices? Are there techniques that the operator can use to reduce the amount of foreign material that is released? This study has gener- 
ated and should generate a heightened sense of alertness regarding this phenomenon.

(http://thejns.org/doi/abs/10.3171/2013.10.JNS132111)

\section{Disclosure}

No funding was obtained for the completion of this manuscript. No ethical guidelines have been violated. Dr. Hoh serves as a consultant for Edge Therapeutics. Dr. Fargen reports no conflict of interest.

\section{References}

1. Becske T, Kallmes DF, Saatci I, McDougall CG, Szikora I, Lanzino G, et al: Pipeline for uncoilable or failed aneurysms: results from a multicenter clinical trial. Radiology 267:858868,2013

2. Brinjikji W, Murad MH, Lanzino G, Cloft HJ, Kallmes DF: Endovascular treatment of intracranial aneurysms with flow diverters: a meta-analysis. Stroke 44:442-447, 2013

3. Chalouhi N, Jabbour P, Tjoumakaris S, Starke RM, Dumont AS, Liu H, et al: Treatment of large and giant intracranial aneurysms: cost comparison of flow diversion and traditional embolization strategies. World Neurosurg [epub ahead of print], 2013

4. Chiu AH, Nadarajah M, Wenderoth JD: Cost analysis of intracranial aneurysmal repair by endovascular coiling versus flow diversion: at what size should we use which method? J Med Imaging Radiat Oncol 57:423-426, 2013

5. Chiu AH, Wenderoth J: Cerebral hyperperfusion after flow diversion of large intracranial aneurysms. J Neurointerv Surg 5:e48, 2013

6. Colby GP, Lin LM, Paul AR, Huang J, Tamargo RJ, Coon AL: Cost comparison of endovascular treatment of anterior circulation aneurysms with the pipeline embolization device and stent-assisted coiling. Neurosurgery 71:944-950, 2012

7. Cruz JP, Chow M, O'Kelly C, Marotta B, Spears J, Montanera $\mathrm{W}$, et al: Delayed ipsilateral parenchymal hemorrhage following flow diversion for the treatment of anterior circulation aneurysms. AJNR Am J Neuroradiol 33:603-608, 2012

8. Fargen KM, Velat GJ, Lawson MF, Mocco J, Hoh BL: Review of reported complications associated with the Pipeline Embolization Device. World Neurosurg 77:403-404, 2012

9. Fischer S, Vajda Z, Aguilar Perez M, Schmid E, Hopf N, Bazner H, et al: Pipeline embolization device (PED) for neurovascular reconstruction: initial experience in the treatment of 101 intracranial aneurysms and dissections. Neuroradiology 54:369-382, 2012

10. Heller RS, Dandamudi V, Lanfranchi M, Malek AM: Effect of antiplatelet therapy on thromboembolism after flow diversion with the Pipeline Embolization Device. Clinical article. J Neurosurg 119:1603-1610, 2013

11. Hu YC, Deshmukh VR, Albuquerque FC, Fiorella D, Nixon RR, Heck DV, et al: Histopathological assessment of fatal ipsilateral intraparenchymal hemorrhages after the treatment of supraclinoid aneurysms with the Pipeline Embolization Device. Report of 3 cases. J Neurosurg [epub ahead of print December 10, 2013. DOI: 10.3171/2013.11.JNS131599]

12. Lylyk P, Miranda C, Ceratto R, Ferrario A, Scrivano E, Luna $\mathrm{HR}$, et al: Curative endovascular reconstruction of cerebral aneurysms with the pipeline embolization device: the Buenos Aires experience. Neurosurgery 64:632-642, 2009

13. McAuliffe W, Wycoco V, Rice H, Phatouros C, Singh TJ, Wenderoth J: Immediate and midterm results following treatment of unruptured intracranial aneurysms with the pipeline embolization device. AJNR Am J Neuroradiol 33:164-170, 2012
14. Velat GJ, Fargen KM, Lawson MF, Hoh BL, Fiorella D, Mocco $\mathrm{J}$ : Delayed intraparenchymal hemorrhage following pipeline embolization device treatment for a giant recanalized ophthalmic aneurysm. J Neurointerv Surg 4:e24, 2012

\section{Response}

Cameron G. McDougall, M.D.

Division of Neurological Surgery, Barrow Neurological Institute, St. Joseph's Hospital and Medical Center, Phoenix, Arizona view.

We thank Drs. Fargen and Hoh for their careful re-

As we noted in our paper, the finding at autopsy of foreign body emboli in the cerebral arteries of patients who have recently undergone neurointerventional procedures is not new. Indeed, the figures from Dr. Barnwell's 1997 article are eerily reminiscent of those that we are now publishing. ${ }^{1}$

A few points bear emphasizing. First, polyvinylpyrrolidone (PVP) is a widely used catheter coating. In addition to the Cook Shuttle Guiding Sheath, several of the devices used in the treatment of the described cases are coated with PVP. Second, the presence of PVP emboli at autopsy does not unequivocally establish these emboli as being responsible for the subsequent hemorrhages. It is certainly possible that multiple other factors could be at play and that the emboli, being common, were only incidentally present.

While recognizing the aforementioned elements of uncertainty, it is nevertheless clear that nothing good can come of such emboli and that every reasonable effort should be made to minimize their occurrence. Additionally, we are in an era of spectacular noninvasive imaging, and we occasionally find ourselves lulled into thinking that no additional information is likely to be gained from something so prosaic as an autopsy. The patients in the cases we described showed us that we know less than we think. Our original motivation for the first two autopsies was to interrogate the integrity of the treated aneurysms and flow diverters, and the finding of the emboli was entirely unexpected. We trust that our colleagues will help us pay respect to the lesson we have learned from our patients by working with us to answer the many excellent questions suggested by Drs. Fargen and Hoh.

\section{Reference}

1. Barnwell SL, D’Agostino AN, Shapiro SL, Nesbit GM, Kel$\operatorname{logg}$ JX: Foreign bodies in small arteries after use of an infusion microcatheter. AJNR Am J Neuroradiol 18:1886-1889, 1997

Please include this information when citing this paper: published online December 10, 2013; DOI: 10.3171/2013.10.JNS132111. 